\title{
Geleitwort des Reihenherausgebers
}

Forschung und Lehre gehören zusammen - eigentlich. Die Studienwirklichkeit unserer Studierenden sieht häufig anders aus, denn zunehmend enger getaktete modularisierte Studiengänge und die oft übergebührliche Beanspruchung der Lehrenden durch Überlast und in der akademischen Selbstverwaltung gewähren immer weniger Raum für die Erfahrung, dass forschendes Lehren schon im Studium zusammengehen kann im gelehrten Gespräch und Austausch, wenn man sich Zeit dafür nimmt und gegenseitig Raum dafür gibt. Es gehört zu den beglückendsten Momenten eines akademischen Lehrers, wenn im Seminar bei der Arbeit am gemeinsamen Gegenstand der Funke überspringt und das geweckte Interesse gegenseitigen Austausch auf Augenhöhe und gemeinsame Entdeckerfreuden möglich macht. Dazu gehört Engagement, Anstrengung und Beharrlichkeit - eine Erfahrung, die Forschung ebenso ausmacht wie die Bereitschaft, gelegentlich auf Freizeit zu verzichten zugunsten längeren Bibliotheksbesuchs und gemeinsamen Ausflügen im Gelände und ins Archiv.

Am Institut für Geschichte der Martin-Luther-Universität gibt es bei allen Beteiligten ein besonderes Bemühen darum, und das prägt die Kultur unserer Arbeit in spürbarem Maße. Selten jedoch fügt es sich, dass eine Lehrveranstaltung über mehrere Semester hindurch das innere Feuer gemeinsamer Forschungsfreuden zu schüren vermag und ein gemeinsam kreiertes Forschungsprojekt zu einem erfolgreichen Ende zu führen gelingt und schließlich sogar ein Buch daraus werden kann.

Klaus Krüger ist zusammen mit seinen Studierenden eine derart überzeugende Leistung gelungen mit einem Projekt, das einerseits mit seinem Fokus auf die spätmittelalterliche und frühneuzeitliche Begräbnis- und Memorialkultur einen ganz wesentlichen Aspekt der Sozial- und Kulturgeschichte der Vormoderne zu beleuchten vermag, andererseits mit seinem Fokus auf den hallischen Stadtgottesacker ein zentrales und in seiner Bedeutung für die Geschichte der Stadt und ihrer Gesellschaft identitätsstiftendes Monument und lebendiges Denkmal erschließt. Wie anders lässt sich an einer solchen Forschungsleistung teilhaben und Gewinn daraus ziehen, als dass sie in Buchgestalt öffentlich verfügbar wird.

Angesichts ihrer Bedeutung für die Geschichte der Stadt Halle, als beindruckendes Bauzeugnis dieses einzigen geschlossenen Campo Santo nördlich der Alpen und der bis heute lebendigen Verwobenheit dieser Totenstätte mit ihrer Stadt ist es gerechtfertigt, 
diese Arbeit ungeachtet ihrer hohen Druckkosten aus frei gehaltenen Forschungsmitteln zu finanzieren und damit der Öffentlichkeit zugänglich zu machen. Dem Herausgeber wie seinen Autoren sei mit großer Anerkennung herzlich gedankt und ihrem gemeinsamen Werk jeglicher Erfolg gewünscht!

Andreas Ranft 